\title{
Analysis of the Sector of Software \& Computer Services with a New Carhart 4-Factor Model
}

\author{
Liuling Li1 ${ }^{1}$ Qingyu Zhu ${ }^{2 *}$, Yang Mu ${ }^{1}$ \\ ${ }^{1}$ Economics School, Nankai University, China \\ ${ }^{2}$ College of Software, Nankai University, China \\ Email: liliuling@nankai.edu.cn, `zhuqingyu_cs@outlook.com, yangmu2016@yahoo.com
}

How to cite this paper: Li, L.L., Zhu, Q.Y. and $\mathrm{Mu}, \mathrm{Y}$. (2017) Analysis of the Sector of Software \& Computer Services with a New Carhart 4-Factor Model. Journal of Mathematical Finance, 7, 65-82. https://doi.org/10.4236/jmf.2017.71004

Received: November 3, 2016

Accepted: January 17, 2017

Published: January 20, 2017

Copyright ( 92017 by authors and Scientific Research Publishing Inc. This work is licensed under the Creative Commons Attribution International License (CC BY 4.0).

http://creativecommons.org/licenses/by/4.0/

Open Access

\begin{abstract}
In this paper, we analyze the sector of Software and Computer Services with a new Carhart four-factor model. The US is the leading world market for this sector and this sector is a source of significant economic opportunity in US. We compare this sector in US, UK and China to find out whether the US phenomenon has been replicated by other industrialized countries. LR, KS and AIC are used for testing parameter restrictions, residual check and model comparison, respectively. MLE is used to estimate parameters via Matlab. Empirical results show the Carhart 4 factors are still alive! The new 4 -factor model fits the data well and has better in-sample fit than that of Carhart (1997) [1] and Fama-French (1993) [2]. This sector in these 3 countries can not earn statistically significant extra Alpha returns. And the Beta value in this sector of US is close to the market.
\end{abstract}

\section{Keywords}

Carhart (1997) 4-Factor (C), Standardized Standard Asymmetric Exponential Power Distribution (SSAEPD), EGARCH

\section{Introduction}

Fama and French (1993) add two more factors such as Size factor and Book-to-market factor into the CAPM model and create a 3-factor model, which is capable to explain the stock returns better than the CAPM. Carhart (1997) finds the momentum factor has great effect on stock returns.

After Carhart (1997), many researches about Carhart 4-factor model have been done. And these researches can be divided into two groups. One group apply this model to different countries and show that this model has powerful explanation (see Panel A of Table 1). For example, this model can explain the stock markets well for Europe in Otten and Bams (2002) [3], China in Guan 
(2011) [4], Netherlands in Lopez (2014) [5].

Others extend this model by finding new factors (see Panel B of Table 1). Fama and French (2012) [6] introduce local and global factors into model. Connor, Hagmann and Linton (2012) [7] find an own-volatility factor. Chai, Fall and Garghori (2013) [8] add Iliquidity factor. Garyn-Tal and Lauterbach (2015) [9] suggest U.S. or global factors to the local model and create a hybrid model. Bradrania, Peat and Satchell (2015) [10] consider Iliquidity factor and Idiosyncratic

Table 1. Researches about the carhart 4-factor model.

\begin{tabular}{|c|c|c|c|c|c|c|c|}
\hline \multirow{2}{*}{ Author (Year) } & \multirow{2}{*}{ Research Purpose } & \multirow{2}{*}{ Model } & \multirow{2}{*}{$\begin{array}{l}\text { Estimation } \\
\text { Method }\end{array}$} & \multirow{2}{*}{$\begin{array}{l}\text { Computer } \\
\text { Algorithm }\end{array}$} & \multicolumn{3}{|c|}{ Data } \\
\hline & & & & & Country & Variables & Frequency \& Period \\
\hline \multicolumn{8}{|c|}{ Panel A: Empirical Applications of Carhart 4-factor Model } \\
\hline Otten et al. (2002) & Empirical Tests & $\mathrm{C}$ & OLS & - & Europe & Mkt, SMB, HML, WML & M1991:1-1998:12 \\
\hline Gallagher et al. (2006) [13] & Empirical Analysis & $\mathrm{C}$ & Regression & - & Australia & Mkt, SMB, HML, WML & M1994:1:2-2001:12:31 \\
\hline Trimech et al. (2009) [14] & Empirical Tests & $\mathrm{C}$ & Wavelet Analysis & - & France & Mkt, SMB, HML, WML & M1985:11-2006:10 \\
\hline ÖNDEŞ et al. (2010) [15] & Model Comparsion & $\mathrm{FF}, \mathrm{C}$ & FIML & - & Turkey & Mkt, SMB, HML, WML & M1996:7-2009:12 \\
\hline Behr et al. (2011) [16] & Empirical Analysis & $\mathrm{C}$ & - & - & US & Mkt, SMB, HML, WML & M1963:7-2008:12 \\
\hline Guan (2011) & Empirical Tests & $\mathrm{C}$ & - & Eviews & China & Mkt, SMB, HML, WML & M2008:7-2010:12 \\
\hline Lopez (2014) & Model Comparsion & CAPM, FF, C & TSR,CSR & - & Netherlands & Mkt, SMB, HML, WML & M2004:1-2014:1 \\
\hline \multicolumn{8}{|c|}{ Panel B: Extensions for Carhart 4-factor Model } \\
\hline Fama et al. (2012) & Model Comparsion & Local and Global C & Regression & - & Four Regions & Mkt, SMB, HML, WML & M1990:11-2011:3 \\
\hline Connor (2012) & Model Extension & FF, C, C with volatility & Kernel & - & US & Mkt, SMB, HML, WML, VOL & M1970-2007 \\
\hline Chai et al. (2013) & Model Extension & $\mathrm{C}$ with Iliquidity & OLS & - & Australia & Mkt, SMB, HML, WML, IML & M1982:1-2010:12 \\
\hline Garyn-Tal et al. (2015) & Model Comparsion & Local and Hybrid C & Regression & - & Israel & Mkt, SMB, HML, WML & M2002:6-2013:7 \\
\hline Bradrania (2015) & Model Extension & $\mathrm{C}$ with Iliquidity and IV & TSR & - & US & Mkt, SMB, HML, WML, IML D & D1958:1:1-2008:12:31 \\
\hline $\mathrm{Mu}(2015)[17]$ & Model Extension & C-SSAEPD-EGARCH & MLE & Matlab & US & Mkt, SMB, HML, WML & M1927:1-2014:12 \\
\hline \multirow{2}{*}{\multicolumn{8}{|c|}{$\begin{array}{l}\text { Notes: “-” means that no information is available in this } \\
\text { Minus Low Book-to-market. WML = Past Winner portf } \\
\text { FIML = Information Maximum Likelihood. Four Regions } \\
\text { lios. Hybrid C is adding U.S. or global factors to the local } \\
\text { Table 2. Researches about the software sector. }\end{array}$}} \\
\hline & & & & & & & \\
\hline Author (Year) & \multicolumn{2}{|c|}{ Research Purpose } & Country & \multicolumn{3}{|c|}{ Variables } & $\begin{array}{l}\text { Frequency } \\
\text { \& Period }\end{array}$ \\
\hline Chatzoglou (2000) [18] & profil & e of firms & US & \multicolumn{3}{|c|}{ size, concentration, investment, profitability, risk } & Y1980-1994 \\
\hline Rubin (2002) [19] & US softw & are industry & US & \multicolumn{3}{|c|}{$\begin{array}{c}\text { spending, quality, process, staffing, employees, } \\
\text { revenue, net income }\end{array}$} & Y1997-2001 \\
\hline Arora (2002) [20] & contribution of $\mathrm{s}$ & oftware to economic & India & \multicolumn{3}{|c|}{ growth of export and domestic revenues, salaries } & Y1984-1998 \\
\hline Kshetri (2005) [21] & major & indicators & China, India & \multicolumn{3}{|c|}{ export, back-office services, annual PC sales } & Y1996-2004 \\
\hline Storz (2008) [22] & & rnings & Japans & \multicolumn{3}{|c|}{ sales, employees, place, year of start-up, type } & - \\
\hline Uzzafer (2010) [23] & financial tool fo & $\mathrm{r}$ risk measurement & - & \multicolumn{3}{|c|}{ financial position, cost, $\mathrm{VaR}, \mathrm{ES}$} & - \\
\hline Genuchten (2012) [24] & compound an & inual growth rate & US & & & - & - \\
\hline
\end{tabular}

Notes: "-" means that no information is available in this paper. VaR = Value-at Risk. ES = Expected Shortfall. CMMI = Capability Maturity Model Integration. $\mathrm{ROA}=$ Return on Assets. 
Volatility (IV) in value-weighted portfolios.

Our research falls into the 2 nd group and tries to extend the 4 -factor model in Carhart (1997). But different from previous researches, instead of introducing different factors, we use a non-normal error of SSAEPD proposed by Zhu and Zinde-Walsh (2009) [11], and the EGARCH-type volatility of Nelson (1991) [12]. We denote our new model as C-SSAEPD-EGARCH. SSAEPD is capable to show the skewness, fat tails and asymmetric kurtosis of data. Based on the new Carhart 4-factor model, we try to test following hypotheses:

1) With EGARCH-type volatilities in Nelson (1991) and non-normal errors of SSAEPD in Zhu and Zinde-Walsh (2009), are the Carhart 4 factors still alive in the sector of Software \& Computer Services?

2) Can this new 4-factor model beat that of Carhart (1997)?

To answer these questions, we run simulation to test the MatLab program used in this paper. Then, the industry of the software \& computer services in US, UK and China are analyzed ${ }^{1}$. Data are downloaded from the Investing.com, and the sample period is from Nov. 1st, 2012 to Sept. 30th, 2015. Method of Maximum Likelihood Estimation is used to estimate the parameters. Likelihood Ratio test (LR) and Kolmogorov-Smirnov test (KS) are used for model diagnostics. Akaike Information Criterion (AIC) is used for model comparison.

We find out the Carhart 4 factors are still alive! The EGARCH-type volatility can capture the excess kurtosis. The new model fits the data well and has better in-sample fit than Fama-French (1993)'s 3-factor model and Carhart (1997)'s 4 -factor model in most cases. The industry of software \& computer services in US, UK and China all cannot earn extra Alpha returns since the constant term in this new model is not statistically significant. This industry in US is similar to the market because the Beta coefficient $\left(\beta_{1}\right)$ is close to 1 .

The organization of this paper is as follows. The model and methodology are discussed in section 2. Empirical results and the model comparisons will be presented in section 3 . Section 4 is the conclusions and future extensions.

\section{Model and Methodology}

\subsection{C-SSAEPD-EGARCH Model}

A new 4-factor model ${ }^{2}$ is used to analyze the sector of software \& computer services sector (denoted as C-SSAEPD-EGARCH) ${ }^{3}$.

$$
\begin{gathered}
R_{t}-R_{f t}=\beta_{0}+\beta_{1}\left(R_{m t}-R_{f t}\right)+\beta_{2} \mathrm{SMB}_{t}+\beta_{3} \mathrm{HML}_{t}+\beta_{4} \mathrm{WML}_{t}+u_{t}, \\
u_{t}=\sigma_{t} z_{t}, z_{t} \sim \operatorname{SSAEPD}\left(\alpha, p_{1}, p_{2}\right), t=1,2, \cdots, T, \\
\ln \left(\sigma_{t}^{2}\right)=a+\sum_{i=1}^{s} g\left(z_{t-i}\right)+\sum_{j=1}^{m} b_{j} \ln \left(\sigma_{t-j}^{2}\right),
\end{gathered}
$$

\footnotetext{
${ }^{1}$ Researches about the software sector are listed in Table 2.

${ }^{2}$ This new model is first suggested in Mu (2014). The EGARCH-type volatility in Nelson (1991) and non-Normal error of SSAEPD in Zhu and Zinde-Walsh (2009) are considered in the new model. We first check the simulation and the empirical results in $\mathrm{Mu}$ (2014). Then, we re-run the simulation by setting other true parameters. The results are listed in Appendix 4.

${ }^{3}$ SSAEPD errors with zero mean and unit variance, instead of AEPD errors, are used to better focus on the EGARCH-type volatility.
} 


$$
\begin{aligned}
g\left(z_{t-i}\right) & =c_{i} z_{t-i}+d_{i}\left[\left|z_{t-i}\right|-E\left(\left|z_{t-i}\right|\right)\right], \\
& = \begin{cases}\left(c_{i}+d_{i}\right) z_{t-i}-d_{i} E\left(\left|z_{t-i}\right|\right), & \text { if } \quad z_{t-i} \geq 0 \\
\left(c_{i}-d_{i}\right) z_{t-i}-d_{i} E\left(\left|z_{t-i}\right|\right), & \text { else. }\end{cases}
\end{aligned}
$$

where $\theta=\left(\beta_{0}, \beta_{1}, \beta_{2}, \beta_{3}, \beta_{4}, \alpha, p_{1}, p_{2}, a,\left\{b_{j}\right\}_{j=1}^{m},\left\{c_{i}\right\}_{i=1}^{s},\left\{d_{i}\right\}_{i=1}^{s}\right)$ are parameters to be estimated.

$R_{t}$ is the rate of return for US, UK and China indices of software \& computer services industry at time $t . R_{f t}$ is the rate of return for the risk-free asset at time $t . R_{m t}$ is the rate of return for the market at time $t . \mathrm{SMB}_{t}$ is the size factor, and stands for small market capitalization minus big market capitalization. $\mathrm{HML}_{t}$ is the value factor, and stands for high book-to-market ratio minus low book-to-market ratio. $\mathrm{WML}_{t}$ is the momentum factor, and stands for high prior return portfolios minus low prior return portfolios at time $t$.

$\beta_{0}, \beta_{1}, \beta_{2}, \beta_{3}, \beta_{4}$ are the coefficient parameters in the regression model. $T$ is the sample size. $\sigma_{t}$ is the conditional standard deviation, i.e., volatility. The error term $z_{t}$ is distributed as the Standardized Standard Asymmetric Exponential Power Distribution (SSAEPD) proposed in Zhu and Zinde-Walsh (2009).

\subsection{Carhart (1997) 4-Factor Model (C Model)}

The 4-factor model proposed in Carhart (1997) is:

$$
\begin{gathered}
R_{t}-R_{f t}=\beta_{0}+\beta_{1}\left(R_{m t}-R_{f t}\right)+\beta_{2} \mathrm{SMB}_{t}+\beta_{3} \mathrm{HML}_{t}+\beta_{4} \mathrm{WML}_{t}+u_{t}, \\
u_{t}=\sigma_{t} z_{t}, z_{t} \sim \operatorname{Normal}\left(\mu, \sigma^{2}\right), t=1,2, \cdots, T .
\end{gathered}
$$

where $\theta=\left(\beta_{0}, \beta_{1}, \beta_{2}, \beta_{3}, \beta_{4}, \mu, \sigma\right)$ are parameters to be estimated in this model. Definitions of variables are the same as before.

\subsection{SSAEPD}

In the new model, the error term $z_{t}$ is distributed as the Standardized Standard Asymmetric Exponential Power Distribution (SSAEPD) proposed in Zhu and Zinde-Walsh (2009). The probability density function (PDF) of $z_{t}$ is:

$$
\begin{aligned}
& f\left(z_{t}\right)=\left\{\begin{array}{l}
\delta\left(\frac{\alpha}{\alpha^{*}}\right) K\left(p_{1}\right) \exp \left(-\frac{1}{p_{1}}\left|\frac{\omega+\delta z_{t}}{2 \alpha^{*}}\right|^{p_{1}}\right), \quad \text { if } z_{t} \leq-\frac{\omega}{\delta}, \\
\delta\left(\frac{1-\alpha}{1-\alpha^{*}}\right) K\left(p_{2}\right) \exp \left(-\frac{1}{p_{2}}\left|\frac{\omega+\delta z_{t}}{2\left(1-\alpha^{*}\right)}\right|^{p_{2}}\right), \quad \text { if } z_{t}>-\frac{\omega}{\delta},
\end{array}\right. \\
& z_{t}=\frac{x_{t}-\omega}{\delta}, \\
& \delta^{2}= \\
& E\left(x_{t}\right)=\frac{1}{B}\left[(1-\alpha)^{2} \frac{p_{2} \Gamma\left(2 / p_{2}\right)}{\Gamma^{2}\left(1 / p_{2}\right)}-\alpha^{2} \frac{p_{1} \Gamma\left(2 / p_{1}\right)}{\Gamma^{2}\left(1 / p_{1}\right)}\right] \\
&-\frac{1}{B^{2}}\left[(1-\alpha)^{2} \frac{1}{B_{2} \Gamma\left(2 / p_{2}\right)} \frac{p^{2}\left(1 / p_{2}\right)}{\Gamma^{2}}\left[(1-\alpha)^{3} \frac{p_{2}^{2} \Gamma\left(3 / p_{2}\right)}{\Gamma^{3}\left(1 / p_{2}\right)}+\alpha^{3} \frac{p_{1}^{2} \Gamma\left(3 / p_{1}\right)}{\Gamma^{3}\left(1 / p_{1}\right)}\right]^{2}\right]
\end{aligned}
$$




$$
\begin{gathered}
K\left(p_{1}\right)=\frac{1}{2 p_{1}^{1 / p_{1}} \Gamma\left(1+1 / p_{1}\right)}, \\
K\left(p_{2}\right)=\frac{1}{2 p_{2}^{1 / p_{2}} \Gamma\left(1+1 / p_{2}\right)}, \\
B=\alpha K\left(p_{1}\right)+(1-\alpha) K\left(p_{2}\right) .
\end{gathered}
$$

$x_{t}$ is distributed as the standard $\operatorname{AEPD(SAEPD).~And~} \Gamma(\cdot)$ is the gamma function. $\alpha \epsilon(0,1)$ is the skewness parameter. $p_{1}>0$ and $p_{2}>0$ are the left and right tail parameters, respectively. When $\alpha=0.5, p_{1}=p_{2}=2$, SSAEPD will be reduced to Standard Normal, i.e., Normal $(0,1)$.

\subsection{MLE}

We estimate the parameters in above models with the method of Maximum Likelihood Estimation (MLE). The maximum likelihood function of the model is

$$
\begin{aligned}
& L\left(\left\{R_{t}-R_{f t}, R_{m t}-R_{f t}\right\}_{t=1}^{T} ; \theta\right) \\
& =\prod_{t=1}^{T} f\left(R_{t}-R_{f t}\right) \\
& =\prod_{t=1}^{T}\left\{\begin{array}{cc}
\frac{\delta}{\sigma_{t}}\left(\frac{\alpha}{\alpha^{*}}\right) K\left(p_{1}\right) \exp \left(-\frac{1}{p_{1}}\left|\frac{\omega+\delta z_{t}}{2 \alpha^{*}}\right|^{p_{1}}\right), & z_{t} \leq-\frac{\omega}{\delta}, \\
\frac{\delta}{\sigma_{t}}\left(\frac{1-\alpha}{1-\alpha^{*}}\right) K\left(p_{2}\right) \exp \left(-\frac{1}{p_{2}}\left|\frac{\omega+\delta z_{t}}{2\left(1-\alpha^{*}\right)}\right|^{p_{2}}\right), & z_{t}>-\frac{\omega}{\delta} .
\end{array}\right.
\end{aligned}
$$

where

$$
\begin{aligned}
& Z_{t}=\frac{R_{t}-R_{f t}-\beta_{0}-\beta_{1}\left(R_{m t}-R_{f t}\right)-\beta_{2} \mathrm{SMB}_{t}-\beta_{3} \mathrm{HML}_{t}-\beta_{4} \mathrm{WML}_{t}}{\sigma_{t}}, \\
& \ln \left(\sigma_{t}^{2}\right)=a+\sum_{i=1}^{s} g\left(z_{t-i}\right)+\sum_{j=1}^{m} b_{j} \ln \left(\sigma_{t-j}^{2}\right), \\
& g\left(z_{t-i}\right)=c_{i} z_{t-i}+d_{i}\left[\left|z_{t-i}\right|-E\left(\left|z_{t-i}\right|\right)\right],
\end{aligned}
$$

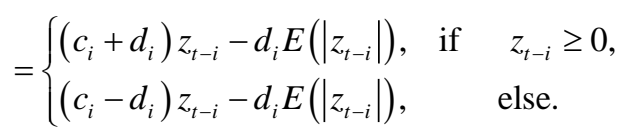

\section{Empirical Analysis}

\subsection{Data}

In this paper, the sector of Software and Computer Services (SCS) is analyzed. Daily data are downloaded from the Investing. $\mathrm{com}^{4} .4$ factors are downloaded from French's Data Library ${ }^{5}$. Sample period is from Nov. 1st, 2012 to Sept. 30th, 2015. Three indices of Software and Computer Services (SCS) for US, UK and P. R. China are compared. To eliminate the heteroscedasticity we calculate the log returns of these indices by following formula: 


$$
r_{i}=100\left(\ln \frac{p_{i, t}}{p_{i, t-1}}\right), i=1,2,3
$$

where $p_{i, t}, \quad p_{i, t-1}$ are the prices of these indices $i$ at time $t$ and $t-1$, respectively.

Table 3 lists the descriptive statistics by Matlab ${ }^{6}$. The values of skewness are not equal to 0 and those of Kurtosis are not 3. Especially, kurtosis values are all greater than 3. P-values of JB tests are 0 , which are smaller than 0.05 . That mean, under 5\% significance level, we can reject the null hypothesis and conclude that data do not follow Normal distribution and non-Normal error of SSAEPD may be proper.

\subsection{Estimation Results}

The estimates are listed in Table 4. For the new model, the Alpha returns for all

Table 3. Descriptive statistics (2012:11:01 to 2015:09:30, Daily).

\begin{tabular}{|c|c|c|c|c|c|c|c|c|}
\hline & Mean & Med. & Max. & Min. & St.De. & Ske. & Kur. & $\mathrm{P}$ \\
\hline US & 0.06 & 0.06 & 5.03 & -4.32 & 1.01 & -0.25 & 5.31 & 0.00 \\
\hline China & 0.12 & 0.21 & 8.37 & -9.68 & 2.63 & -0.54 & 4.64 & 0.00 \\
\hline UK & 0.07 & 0.04 & 4.37 & -3.16 & 0.98 & 0.37 & 4.62 & 0.00 \\
\hline $\mathrm{ME}$ & 0.06 & 0.11 & 3.68 & -3.90 & 0.81 & -0.43 & 5.11 & 0.00 \\
\hline SMB & 0.00 & 0.02 & 1.79 & -1.57 & 0.47 & 0.03 & 3.92 & 0.00 \\
\hline HML & -0.01 & -0.03 & 2.06 & -1.32 & 0.39 & 0.52 & 5.43 & 0.00 \\
\hline WML & 0.04 & 0.05 & 1.99 & -2.64 & 0.58 & -0.37 & 4.59 & 0.00 \\
\hline
\end{tabular}

Notes: Med. = Median, Max. = Maximum, Min. = Minimum. St.De. = Standard Devistion, Ske. = Skewness, Kur. = Kurtosis, P = P-value of Jarque-Bera Test. $\mathrm{ME}=$ Market Excess Return, SMB=Small minus Big, HML = High minus Low, WML = Momentum Factor. The null hypothesis of JB test is H_\{0 $\}$ : Data are distributed as Normal $(0,1)$

Table 4. Estimates.

\begin{tabular}{|c|c|c|c|c|c|c|c|c|c|c|c|c|c|c|}
\hline & $\beta_{0}$ & $\beta_{1}$ & $\beta_{2}$ & $\beta_{3}$ & $\beta_{4}$ & $\alpha$ & $p_{1}$ & $p_{2}$ & $\mu$ & $\sigma$ & $a$ & $b$ & $c$ & $d$ \\
\hline & \multicolumn{14}{|c|}{ Panel A: C-SSAEPD-EGARCH } \\
\hline UK & $0.04^{*}$ & $0.44^{*}$ & $0.05^{\star}$ & $0.07^{\star}$ & $0.18^{*}$ & $0.42^{*}$ & $1.50^{*}$ & $1.50^{*}$ & - & - & $-0.09^{*}$ & $0.56^{*}$ & $0.05^{*}$ & $0.24^{\star}$ \\
\hline US & $-0.01^{\star}$ & $1.08^{*}$ & $-0.09^{*}$ & $-0.37^{\star}$ & $-0.03^{*}$ & $0.51^{\star}$ & $1.50^{*}$ & $1.50^{*}$ & - & - & $-1.71^{\star}$ & $-0.17^{\star}$ & $-0.11^{\star}$ & $0.48^{*}$ \\
\hline \multirow[t]{2}{*}{ China } & $0.15^{\star}$ & $0.21^{\star}$ & $0.22^{*}$ & $-0.21^{\star}$ & $-0.02^{\star}$ & $0.51^{\star}$ & $1.40^{*}$ & $1.80^{*}$ & - & - & $0.13^{*}$ & $0.93^{*}$ & $0.01^{*}$ & $0.31^{*}$ \\
\hline & \multicolumn{14}{|c|}{ Panel B: C-Normal } \\
\hline UK & $0.04^{*}$ & $0.42^{*}$ & $0.09^{*}$ & $0.15^{\star}$ & $0.20^{*}$ & - & - & - & 0.00 & 0.90 & - & - & - & - \\
\hline US & $-0.01^{\star}$ & $1.07^{*}$ & $-0.10^{*}$ & $-0.48^{\star}$ & $-0.04^{*}$ & - & - & - & 0.00 & 0.48 & - & - & - & - \\
\hline \multirow[t]{2}{*}{ China } & $0.11^{\star}$ & $0.35^{\star}$ & $0.20^{*}$ & $-0.26^{*}$ & $-0.35^{\star}$ & - & - & - & 0.00 & 2.61 & & & & \\
\hline & \multicolumn{14}{|c|}{ Panel C: FF-Normal } \\
\hline US & $-0.01^{\star}$ & $1.06^{\star}$ & $-0.10^{*}$ & $-0.45^{\star}$ & - & - & - & - & 0.00 & 0.48 & - & - & - & - \\
\hline China & $0.10^{*}$ & $0.31^{\star}$ & $0.21^{\star}$ & $-0.03^{*}$ & - & - & - & - & 0.00 & 2.61 & - & - & - & - \\
\hline
\end{tabular}

Notes: C-Normal is the model used in Carhart (1997). FF-Normal is the model used in Fama-French (1993).

${ }^{6}$ Excess returns are got by portfolio returns minus the risk free rate. 
data are small. The Alpha return in China is 0.15 , much higher than those in UK and US. And the values of Beta $\left(\beta_{1}\right)$ for US are the largest and those for China are the smallest. Especially about US, the values of $\beta_{1}$ for all models are very close to 1 , which indicates that US software and computer services sector is similar to the market. SSAEPD can capture the fat-tailness and asymmetric kurtosis in the data. All values of $p_{1}, p_{2}$ are smaller than 2 and that of $\alpha$ are not equal to 0.5. Furthermore, we find out the EGARCH term can better capture the excess kurtosis than non-Normal error. For 4 factor models, their estimates are very close to those of 3 factor models.

\subsubsection{Carhart 4-Factor Still Alive}

- Significant Tests for Parameter Restrictions

Likelihood Ratio test (LR) ${ }^{7}$ is used to test the significance of regressors in these models. The P-values for LR tests are listed in Table 5.

We find out with non-Normal errors such as SSAEPD and EGARCH-type volatilities, the Carhart 4 factors are still alive in the sector of Software \& Computer Services. Panel A of Table 5 lists the results for the C-SSAEPD-EGARCH model. For example, the null hypothesis of the joint significance test is $H_{0}: \beta_{1}=\beta_{2}=\beta_{3}=\beta_{4}=0$ and the P-values of the joint significance test for UK, US and China are all approximately equal to 0 , which means the coefficient of $\beta_{0}, \beta_{1}, \beta_{2}, \beta_{3}$ and $\beta_{4}$ are statistically joint significance under $5 \%$ level. The individual significance tests show UK and US coefficient $\beta_{1}$ is statistically significant. That is, market returns have significant effect on this sector returns of UK

Table 5. P-values of likelihood ratio test (LR).

\begin{tabular}{|c|c|c|c|c|c|c|c|c|c|c|c|c|c|c|c|}
\hline & $\mathrm{T} 1$ & $\mathrm{~T} 2$ & T3 & $\mathrm{T} 4$ & T5 & T6 & T7 & T8 & T9 & $\mathrm{T} 10$ & T11 & $\mathrm{T} 12$ & T13 & $\mathrm{T} 14$ & T15 \\
\hline & \multicolumn{15}{|c|}{ Panel A: C-SSAEPD-EGARCH } \\
\hline UK & $0^{*}$ & 0.65 & $0^{*}$ & 0.98 & 0.81 & 0.66 & $0^{*}$ & 0.25 & $0^{*}$ & $0^{*}$ & $0.01^{*}$ & 0.09 & 0.13 & 0.92 & $0.03^{*}$ \\
\hline US & $0^{*}$ & 0.99 & $0^{*}$ & 0.35 & $0^{*}$ & 0.87 & $0^{*}$ & 0.89 & $0^{*}$ & $0^{*}$ & $0^{*}$ & $0^{*}$ & 0.73 & 0.83 & $0^{*}$ \\
\hline \multirow[t]{2}{*}{ China } & $0^{*}$ & 0.35 & 0.77 & 0.56 & 0.92 & 0.99 & $0^{*}$ & 0.99 & $0^{*}$ & 1 & $0^{*}$ & $0^{*}$ & $0^{*}$ & 0.99 & $0^{*}$ \\
\hline & \multicolumn{15}{|c|}{ Panel B: C-Normal } \\
\hline UK & $0^{*}$ & 1 & $0^{*}$ & 0.84 & 0.74 & 0.09 & - & - & - & - & - & - & - & - & - \\
\hline US & $0^{*}$ & 1 & $0^{*}$ & 0.19 & $0^{*}$ & 0.83 & - & - & - & - & - & - & - & - & - \\
\hline China & $0.02^{*}$ & 1 & 0.10 & 0.94 & 0.94 & 0.54 & - & - & - & - & - & - & - & - & - \\
\hline
\end{tabular}

Panel C: FF-Normal

\begin{tabular}{cccccccccccc}
\hline UK & $0^{*}$ & 1 & 1 & 1.00 & 1 & - & - & - & - & - & - \\
US & 1 & 1 & $0 *$ & 0.87 & 1 & - & - & - & - & - & - \\
China & 1 & 1 & 1 & 1.00 & 1 & - & - & - & - & - & - \\
\hline
\end{tabular}

Notes: T1 means H0: $\beta_{1}=\beta_{2}=\beta_{3}=\beta_{4}=0$ for Panel A and B; T1 means H0: $\beta_{1}=\beta_{2}=\beta_{3}=0$ for Panel C; T2 means H0: $\beta_{0}=0$; T3 means H0: $\beta_{1}=0$; T4 means H0: $\beta_{2}=0$; T5 means H0: $\beta_{3}=0$; T6 means H0: $\beta_{4}=0$; T7 means H0: $\alpha=0.5$, $p_{1}=p_{2}=2$; T8 means H0: $\alpha=0.5$; T9 means H0: $p_{1}=2$; T10 means H0: $p_{2}=2$; T11 means H0: $a=b=c=d=0$; T12 means H0: $a=0$; T13 means H0: $b=0$; T14 means H0: $c=0$; T15 means H0: $d=0$; ${ }^{\star}$ means the null hypothesis is rejected under $5 \%$ significance level.

${ }^{7}$ LR formula is from Neyman and Pearson (1993). The equation is:

$L R=-2 \ln ($ likelihood for null $)+2 \ln ($ likelihood for alternative $)$. 
and US. This sector in these 3 countries all don't have a statistically significant coefficient $\beta_{0}$ under $5 \%$ significance level which means they cannot earn statistically significant Alpha returns. Non-Normality is confirmed (see column T7). ARCH and GARCH terms should be added into Carhart 4-factor model since they are all statistically significant (see column T11).

- Kolmogorov-Smirnov Test for Residuals

We check the residuals for models with Kolmogorov-Smirnov test (KS). The $\mathrm{P}$-values of KS test are listed in Table 6, which shows only the residuals of the new Carhart 4-factor model passes the residual diagnostics.

\subsubsection{Model Comparison}

We compare the models with AIC (see Table 7). C-SSAEPD-EGARCH model have smaller values, which means the new model is better than Carhart 4-factor and Fama-French 3-factor.

Table 6. P-values of KS test.

\begin{tabular}{cccc}
\hline model & C-SSAEPD-EGARCH & C-Normal & F-Normal \\
\hline UK & 0.62 & 0.00 & 0.00 \\
US & 0.37 & 0.00 & 0.00 \\
China & 0.91 & 0.00 & 0.00 \\
\hline
\end{tabular}

Note: The null hypothesis of KS test is H0: Data follow a specified distribution. We set the significance level of all tests at $5 \%$. If the P-value of KS test is bigger than 5\%, then we do not reject the null hypothesis. Otherwise, we reject the null hypothesis. For example, we apply KS test for the C-SSAEPD-EGARCH model residuals with the null hypothesis of H0: C-SSEAPD-EGARCH model residuals are distributed as SSAEPD $\left(\hat{\alpha}, \hat{p}_{1}, \hat{p}_{2}\right)$. For US, its $\mathrm{P}$-value is 0.37 , which is bigger than 0.05 . That means, under $5 \%$ significance level, we cannot reject the null hypothesis and conclude that the residuals from C-SSEAPD-EGARCH model follow SSAEPD.

Table 7. AIC values.

\begin{tabular}{|c|c|c|c|c|c|c|c|c|c|c|c|c|c|c|c|c|}
\hline & M1 & M2 & M3 & M4 & M5 & M6 & M7 & M8 & M9 & M10 & M11 & M12 & M13 & M14 & M15 & M16 \\
\hline & \multicolumn{16}{|c|}{ Panel A: C-SSAEPD-EGARCH } \\
\hline UK & $2.59^{*}$ & 2.60 & 2.75 & 2.59 & 2.60 & 2.60 & 2.83 & 2.64 & 2.60 & 2.63 & 2.63 & 2.61 & 2.60 & 2.60 & 2.61 & 2.61 \\
\hline US & $1.29^{*}$ & 1.29 & 2.74 & 1.30 & 1.41 & 1.29 & 3.17 & 1.38 & 1.29 & 1.38 & 1.34 & 1.81 & 1.30 & 1.29 & 2.59 & 1.48 \\
\hline \multirow[t]{2}{*}{ China } & $4.50^{*}$ & 4.51 & 4.50 & 4.51 & 4.50 & 4.50 & 4.51 & 4.53 & 4.50 & 4.52 & 4.50 & 4.62 & 5.88 & 4.50 & 4.66 & 5.99 \\
\hline & \multicolumn{16}{|c|}{ Panel B: C-Normal } \\
\hline UK & $2.65^{*}$ & 2.65 & 2.78 & 2.65 & 2.65 & 2.66 & 2.81 & - & - & - & - & - & - & - & - & - \\
\hline US & $1.41^{*}$ & 1.41 & 2.79 & 1.42 & 1.51 & 1.41 & 2.88 & - & - & - & - & - & - & - & - & - \\
\hline \multirow[t]{2}{*}{ China } & $4.77^{*}$ & 4.77 & 4.78 & 4.77 & 4.77 & 4.78 & 4.79 & - & - & - & - & - & - & - & - & - \\
\hline & \multicolumn{16}{|c|}{ Panel C: FF-Normal } \\
\hline UK & $2.66^{*}$ & 2.66 & 2.80 & 2.66 & 2.66 & - & 2.81 & - & - & - & - & - & - & - & - & - \\
\hline US & $1.41^{*}$ & 1.41 & 2.81 & 1.42 & 1.52 & - & 2.87 & - & - & - & - & - & - & - & - & - \\
\hline China & $4.78^{*}$ & 4.78 & 4.78 & 4.78 & 4.78 & - & 4.79 & - & - & - & - & - & - & - & - & - \\
\hline
\end{tabular}

Notes: ${ }^{\star}$ marks the smallest AIC value for each return. For Panel A, B and C, M1 means C-SSAEPD-EGARCH, C-Normal or FF-Normal. M2 means M1 with $\beta_{0}=0$. M3 means M1 with $\beta_{1}=0$. M4 means M1 with $\beta_{2}=0$. M5 means M1 with $\beta_{3}=0$. M6 means M1 with $\beta_{4}=0$. M7 means M1 with $\beta_{1}=\beta_{2}=\beta_{3}=\beta_{4}=0$ for Panel A and B. M7 means M1 with $\beta_{1}=\beta_{2}=\beta_{3}=0$ for Panel C. M8 means M1 with $\alpha=0.5, p_{1}=p_{2}=2$. M9 means M1 with $\alpha=0.5$. M10 means M1 with $p_{1}=2$. M11 means M1 with $p_{2}=2$. M12 means M1 with $a=0$. M13 means M1 with $b=0$. M14 means M1 with $c=0$. M15 means M1 with $d=0$. M16 means M1 with $a=b=c=d=0$. 


\section{Conclusion and Future Extensions}

In this paper, sector of the software and computer services is studied. A new Carhart 4-factor model (denoted as C-SSAEPD-EGARCH) is empirically tested using data in US, UK and China. This new model uses the non-normal error term of SSAEPD of Zhu and Zinde-Walsh (2009) and EGARCH type volatility of Nelson (1991) to extend the 4 factor model of Carhart (1997). Software sector indices from Investing.com are analyzed. Sample period is Nov. 1st, 2012 to Sept. 30th, 2015. Likelihood Ratio test (LR) is used for parameter restriction test, Kolmogorov-Smirnov test (KS) for residual check and AIC for model comparison. Maximum Likelihood Estimation method (MLE) is used to estimate models via MatLab.

Empirical results show: 1) with EGARCH-type volatilities and non-normal errors, the Carhart 4 factors are still alive in US! 2) The new model fits the data well and has better in-sample fit than Fama-French (1993)'s 3-factor and Carhart(1997)'s 4-factor model. 4) Software \& computer services sector cannot earn extra Alpha returns in US, UK and China. 5) The Beta coefficients of the US are close to 1 .

Future extensions will include but not limited to follow. First, we can construct a new index for software \& computer services sector. Secondly, the markets in other different countries can be compared. Lastly, the new model can be compared with other models such as Fama-French (2015) 5-factor.

\section{References}

[1] Carhart, M.M. (1997) On Persistence in Mutual Fund Performance. The Journal of Finance, 52, 57-82. https://doi.org/10.1111/j.1540-6261.1997.tb03808.x

[2] Fama, E.F. and French, K.R. (1993) Common Risk Factors in the Returns on Stocks and Bonds. Journal of Financial Economics, 33, 3-56. https://doi.org/10.1016/0304-405X(93)90023-5

[3] Otten, R. and Bams, D. (2002) European Mutual Fund Performance. European Financial Management, 8, 75-101. https://doi.org/10.1111/1468-036X.00177

[4] Chen, G. (2011) An Empirical Study on the Performance of Open-End Funds in China Based on Carhart Four-Factor Model. Dissertation Submitted for the Degree of Master, University of International Business and Economics, Beijing. (In Chinese)

[5] Lopez, N.H.L.Y. (2014) On the Robustness of the CAPM, Fama-French Three-Factor Model and the Carhart Four-Factor Model on the Dutch Stock Market. A Dissertation Submitted for the Degree of Master, Tilburg University, Tilburg.

[6] Fama, E.F. and French, K.R. (2012) Size, Value, and Momentum in International Stock Returns. Journal of Financial Economics, 105, 457-472. https://doi.org/10.1016/j.jfineco.2012.05.011

[7] Connor, G., Hagmann, M. and Linton, O. (2012) Efficient Semiparametric Estimation of the Fama-French Model and Extensions. Econometrica, 80, 713-754. https://doi.org/10.3982/ECTA7432

[8] Chai, D., Faff, R. and Gharghori, P. (2013) Liquidity in Asset Pricing: New Australian Evidence Using Low-Frequency Data. Australian Journal of Management, 38, 375-400. https://doi.org/10.1177/0312896213489143 
[9] Garyn-Tal, S. and Lauterbach, B. (2015) The Formulation of the Four Factor Model When a Considerable Proportion of Firms Is Dual-Listed. Emerging Markets Review, 24, 1-12. https://doi.org/10.1016/j.ememar.2015.05.006

[10] Bradrania, M.R., Peat, M. and Satchell, S. (2015) Liquidity Costs, Idiosyncratic Volatility and Expected Stock Returns. International Review of Financial Analysis, 42, 394-406. https://doi.org/10.1016/j.irfa.2015.09.005

[11] Zhu, D. and Zinde-Walsh, V. (2009) Properties and Estimation of Asymmetric Exponential Power Distribution. Journal of Econometrics, 148, 86-99. https://doi.org/10.1016/j.jeconom.2008.09.038

[12] Nelson, D.B. (1991) Conditional Heteroskedasticity in Asset Returns: A New Approach. Econometrica, 59, 347-370. https://doi.org/10.2307/2938260

[13] Gallagher, D.R., Nadarajah, P. and Pinnuck, M. (2006) Top Management Turnover: An Examination of Portfolio Holdings and Fund Performance. Australian Journal of Management, 31, 265-292. https://doi.org/10.1177/031289620603100205

[14] Trimech, A. and Kortas, H. (2009) Multiscale Carhart Four-Factor Pricing Model: Application to the French Market. The ICFAI University Journal of Financial Risk Management, 5, 61-75.

[15] Öndes, T. and Bali, S. (2010) In the Context of the Ise Comparison of FamaFrench's 3 Factor Model and Carhart's 4 Factor Model 1996-2009. Ataturk University Journal of Economics \& Administrative Science, 24, 243-258.

[16] Behr, P., Guettler, A. and Truebenbach, F. (2012) Using Industry Momentum to Improve Portfolio Performance. Journal of Banking \& Finance, 36, 1414-1423. https://doi.org/10.1016/j.jbankfin.2011.12.007

[17] Mu, Y. (2015) A New 4-Factor Model Considering Momentum Factor, FamaFrench 3-Factor, SSAEPD Errors and EGARCH-Type Volatilities. A Dissertation Submitted for the Degree of Bachelor, Nankai University, Tianjin. (In Chinese)

[18] Chatzoglou, P.D. and Vafeas, N. (2000) The Financial Profile of the Software Industry between 1980 and 1994. Information and Software Technology, 42, 755-763. https://doi.org/10.1016/S0950-5849(00)00116-6

[19] Rubin, H., Johnson, M. and Iventosch, S. (2002) The US Software Industry. IEEE Software, 19, 95-97. https://doi.org/10.1109/52.976948

[20] Arora, A. and Athreye, S. (2002) The Software Industry and India's Economic Development. Information Economics and Policy, 14, 253-273. https://doi.org/10.1016/S0167-6245(01)00069-5

[21] Kshetri, N. (2005) Structural Shifts in the Chinese Software Industry. IEEE Software, 22, 86-93. https://doi.org/10.1109/MS.2005.107

[22] Storz, C. (2008) Dynamics in Innovation Systems: Evidence from Japan's Game Software Industry. Research Policy, 37, 1480-1491. https://doi.org/10.1016/j.respol.2008.05.007

[23] Uzzafer, M. (2010) A Financial Tool for Software Risk Measurement. International Conference on Information Science and Applications, Seoul, 21-23 April 2010, 1-6. https://doi.org/10.1109/icisa.2010.5480537

[24] Van Genuchten, M. and Hatton, L. (2012) Compound Annual Growth Rate for Software. IEEE Software, 29, 19-21. https://doi.org/10.1109/MS.2012.79 


\section{Appendix 1. Data Sources}

The indices about Software and Computer Services are obtained from the Investing.com.

1) Dow Jones (DJUSSV), 2012:11:01-2015:09:30.

2) FTSE 350 (TRINMX9530), 2012:11:01-2015:09:30, 2003:10-2015:10.

3) FTSE China A 600 (FTXIN49530), 2012:11:01-2015:09:30.

US, UK and China have different festivals. For example, China stock market is closed during China Spring Festival while US and UK stock markets are still trading. Hence, we delete all the missing data and get 674 sets of data.

\section{Appendix 2. SSAEPD}

According to Zhu and Zinde-Walsh (2009), the AEPD density has following form ${ }^{8}$ :

$$
f_{\mathrm{AEPD}}(x)=\left\{\begin{array}{l}
\left(\frac{\alpha}{\alpha^{*}}\right) \frac{1}{\sigma} K\left(p_{1}\right) \exp \left(-\frac{1}{\left.p_{1}\left|\frac{x-\mu}{2 \alpha^{*} \sigma}\right|^{p_{1}}\right),} \quad \text { if } \quad x \leq \mu,\right. \\
\left(\frac{1-\alpha}{1-\alpha^{*}}\right) \frac{1}{\sigma} K\left(p_{2}\right) \exp \left(-\frac{1}{p_{2}}\left|\frac{x-\mu}{2\left(1-\alpha^{*}\right) \sigma}\right|^{p_{2}}\right), \text { if } x>\mu .
\end{array}\right.
$$

where $\theta=\left(\alpha, p_{1}, p_{2}, \mu, \sigma\right)$ is the parameter vector. $\mu \in R$ and $\sigma>0$ represent location and scale, respectively ${ }^{9} . \alpha \in(0,1)$ is the skewness parameter. $p_{1}>0$ and $p_{2}>0$ are the left and the right tail parameters, respectively. $K(p)$ and $\alpha^{*}$ are defined as

$$
\begin{gathered}
K(p)=\frac{1}{2 p^{1 / p} \Gamma(1+1 / p)}, \\
\alpha^{*}=\frac{\alpha K\left(p_{1}\right)}{\alpha K\left(p_{1}\right)+(1-\alpha) K\left(p_{2}\right)} .
\end{gathered}
$$

If we set the location parameter $\mu=0$ and the scale parameter $\sigma=1$, then we say $X$ is a random variable distributed as Standard AEPD, denote it as $X \sim \operatorname{SAEPD}\left(\alpha, p_{1}, p_{2}, 0,1\right)$. Its $\operatorname{PDF}^{10}$, mean and variance are

${ }^{8} \mathrm{~A}$ convenient reparametrization of Equation (19) is obtained by rescaling, where

$$
f_{\text {AEPD }}(x)=\left\{\begin{array}{c}
\frac{1}{\sigma} \exp \left(-\frac{1}{p_{1}}\left|\frac{x-\mu}{2 \alpha \sigma K\left(p_{1}\right)}\right|^{p_{1}}\right), \text { if } x \leq \mu, \\
\frac{1}{\sigma} \exp \left(-\frac{1}{p_{2}}\left|\frac{x-\mu}{2(1-\alpha) \sigma K\left(p_{2}\right)}\right|^{p_{2}}\right), \text { if } x>\mu . \\
\theta=\left(\alpha, p_{1}, p_{2}, \mu, \sigma\right)
\end{array}\right.
$$

${ }^{9}$ In this case, $\mu$ and $\sigma$ are not the notations for the population mean and the population standard variance.

${ }^{10} \mathrm{~A}$ convenient reparametrization of Equation (19) is obtained by rescaling, where

$$
f_{\text {SAEPD }}(x)=\left\{\begin{array}{c}
\exp \left(-\frac{1}{p_{1}}\left|\frac{x}{2 \alpha K\left(p_{1}\right)}\right|^{p_{1}}\right), \quad \text { if } \quad x \leq 0, \\
\exp \left(-\frac{1}{p_{2}}\left|\frac{x}{2(1-\alpha) K\left(p_{2}\right)}\right|^{p_{2}}\right), \quad \text { if } \quad x>0 . \\
\theta=\left(\alpha, p_{1}, p_{2}, 0,1\right)
\end{array}\right.
$$




$$
\begin{aligned}
& f_{\mathrm{SAEPD}}(x)=\left\{\begin{array}{l}
\left(\frac{\alpha}{\alpha^{*}}\right) K\left(p_{1}\right) \exp \left(-\frac{1}{p_{1}}\left|\frac{x}{2 \alpha^{*}}\right|^{p_{1}}\right), \quad \text { if } \quad x \leq 0, \\
\left(\frac{1-\alpha}{1-\alpha^{*}}\right) K\left(p_{2}\right) \exp \left(-\frac{1}{p_{2}}\left|\frac{x}{2\left(1-\alpha^{*}\right)}\right|^{p_{2}}\right), \quad \text { if } x>0,
\end{array}\right. \\
& E(X)=\frac{1}{B}\left[(1-\alpha)^{2} \frac{p_{2} \Gamma\left(2 / p_{2}\right)}{\Gamma^{2}\left(1 / p_{2}\right)}-\alpha^{2} \frac{p_{1} \Gamma\left(2 / p_{1}\right)}{\Gamma^{2}\left(1 / p_{1}\right)}\right], \\
& \operatorname{Var}(X)=\frac{1}{B^{2}}\left\{(1-\alpha)^{3} \frac{p_{2}^{2} \Gamma\left(3 / p_{2}\right)}{\Gamma^{3}\left(1 / p_{2}\right)}+\alpha^{2} \frac{p_{1}^{2} \Gamma\left(3 / p_{1}\right)}{\Gamma^{3}\left(1 / p_{1}\right)},\right. \\
& \left.-\left[(1-\alpha) \frac{p_{2} \Gamma\left(2 / p_{2}\right)}{\Gamma^{2}\left(1 / p_{2}\right)}-\alpha^{2} \frac{p_{1} \Gamma\left(2 / p_{1}\right)}{\Gamma^{2}\left(1 / p_{1}\right)}\right]^{2}\right\} .
\end{aligned}
$$

Then, if we standardize $X$ with its mean and standard deviation, We can get $Z=\frac{X-E(X)}{\sqrt{\operatorname{Var}(X)}}$, which we call Standardized Standard AEPD (SSAEPD). The $\mathrm{PDF}$ of $\mathrm{Z}$ can be got by transformation.

$$
\begin{aligned}
f_{\text {SSAEPD }}(Z) & =|J| f_{\text {SAEPD }}(E(X)+Z \sqrt{\operatorname{Var}(X)}), \\
& =\delta f_{\text {SAEPD }}(\omega+Z \delta) .
\end{aligned}
$$

where $\omega=E(X), \delta=\sqrt{\operatorname{Var}(X)}$. We can get the probability density function $(\mathrm{PDF})$ of the SSAEPD

$$
f_{\text {SSAEPD }}(z)=\left\{\begin{array}{l}
\delta\left(\frac{\alpha}{\alpha^{*}}\right) K\left(p_{1}\right) \exp \left(-\frac{1}{p_{1}}\left|\frac{\omega+z \delta}{2 \alpha^{*}}\right|^{p_{1}}\right), \quad \text { if } \quad z \leq-\frac{\omega}{\delta}, \\
\delta\left(\frac{1-\alpha}{1-\alpha^{*}}\right) K\left(p_{2}\right) \exp \left(-\frac{1}{p_{2}}\left|\frac{\omega+z \delta}{2\left(1-\alpha^{*}\right)}\right|^{p_{2}}\right), \text { if } z>-\frac{\omega}{\delta} .
\end{array}\right.
$$

$E(z)=0, \operatorname{Var}(z)=1$. With $\alpha=0.5, p_{1}=p_{2}=2$, SSAEPD reduces to Normal $(0,1)$.

\section{Appendix 3. Probability Density Function (PDF) for Model Reduals}

We draw PDFs of model residuals and compare them with theoretical PDFs such as SSAEPD and Normal, respectively. For C-SSAEPD-EGARCH model, the comparisons of PDFs between reduals $\hat{z}_{t}$ and SSAEPD $\left(\hat{\alpha}, \hat{p}_{1}, \hat{p}_{2}\right)$ are plotted in Figure 1. These two curves are very close to each others for UK, China and US, respectively. Therefore, by method of "eye-rolling", we conclude the new model fit data well. Figure 2 and Figure 3 show the comparisons of PDFs between reduals $\hat{u}_{t}$ and Normal $(\hat{\mu}, \hat{\sigma})$ for Carhart 4-factor model and Fama-French 3-factor model respectively. These differences are larger than those in Figure 1, which further show that the new model fit data better. 


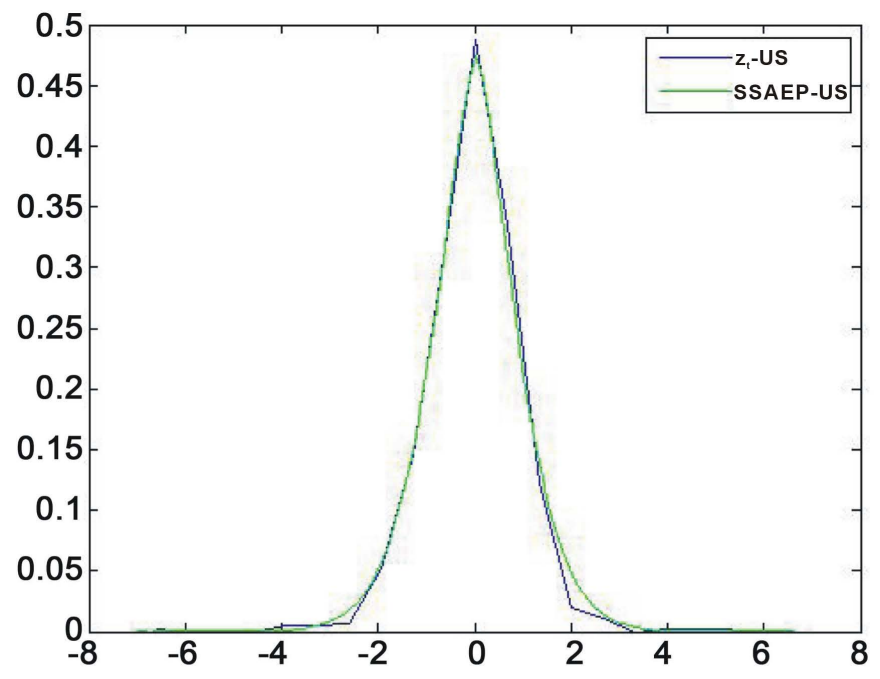

(a) PDF for US

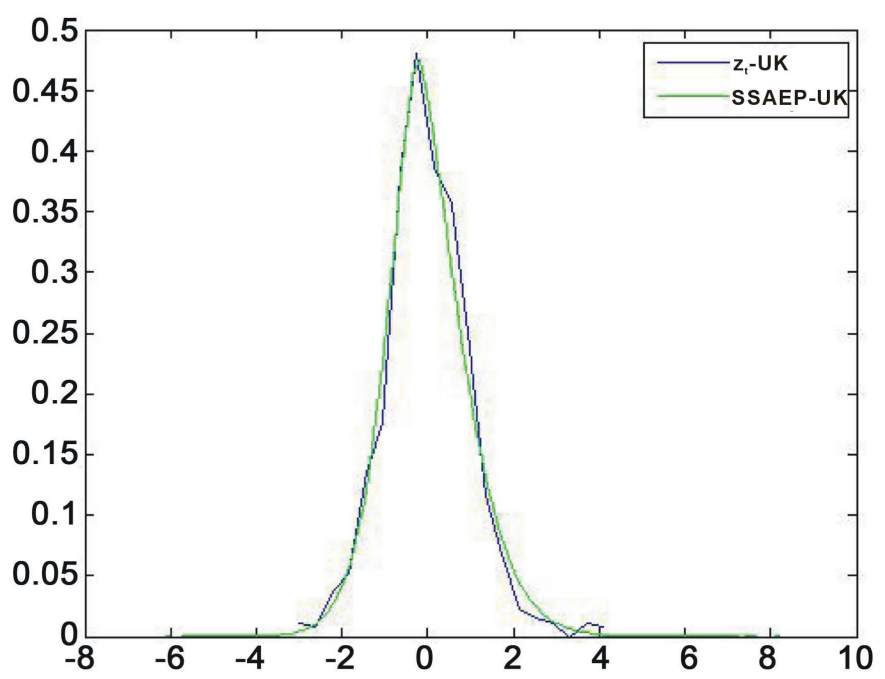

(b) PDF for UK

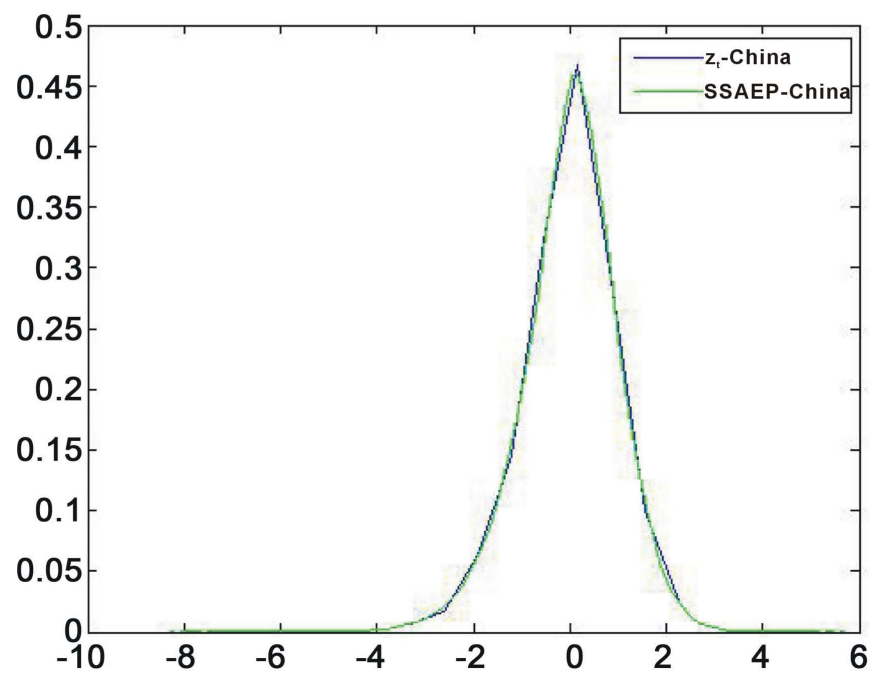

(c) PDF for China

Figure 1. PDFs for reduals $\hat{z}_{t}$ and SSAEPD $\left(\hat{\alpha}, \hat{p}_{1}, \hat{p}_{2}\right)$, C-SSAEPD-EGARCH model. 


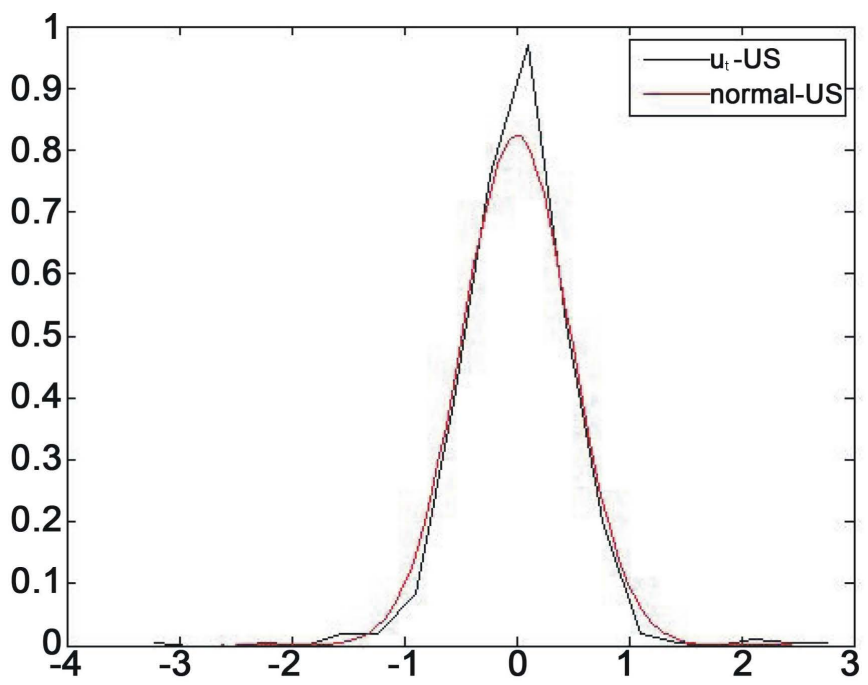

(a) PDF for US

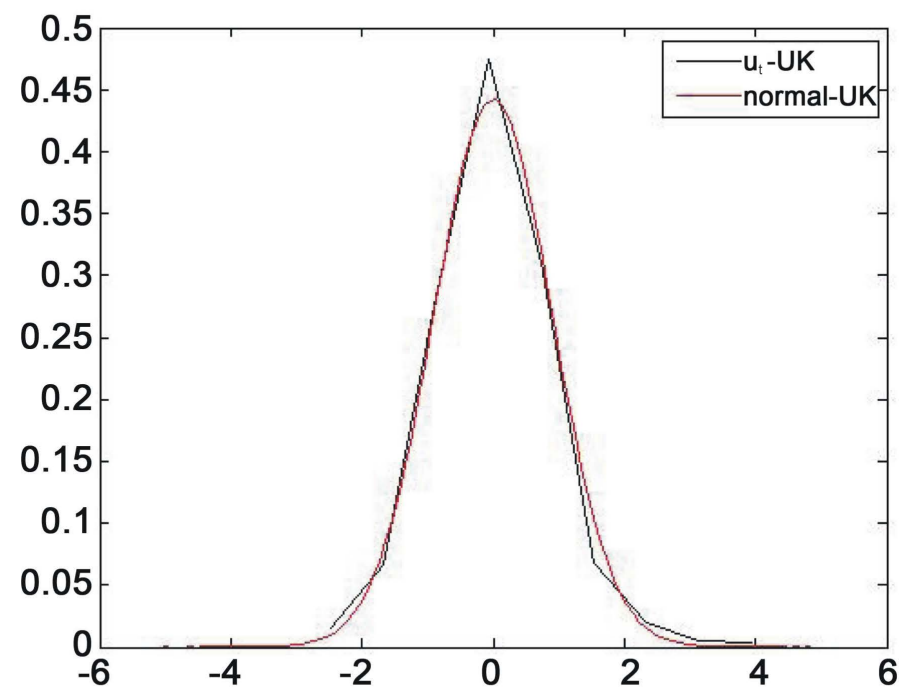

(b) PDF for UK

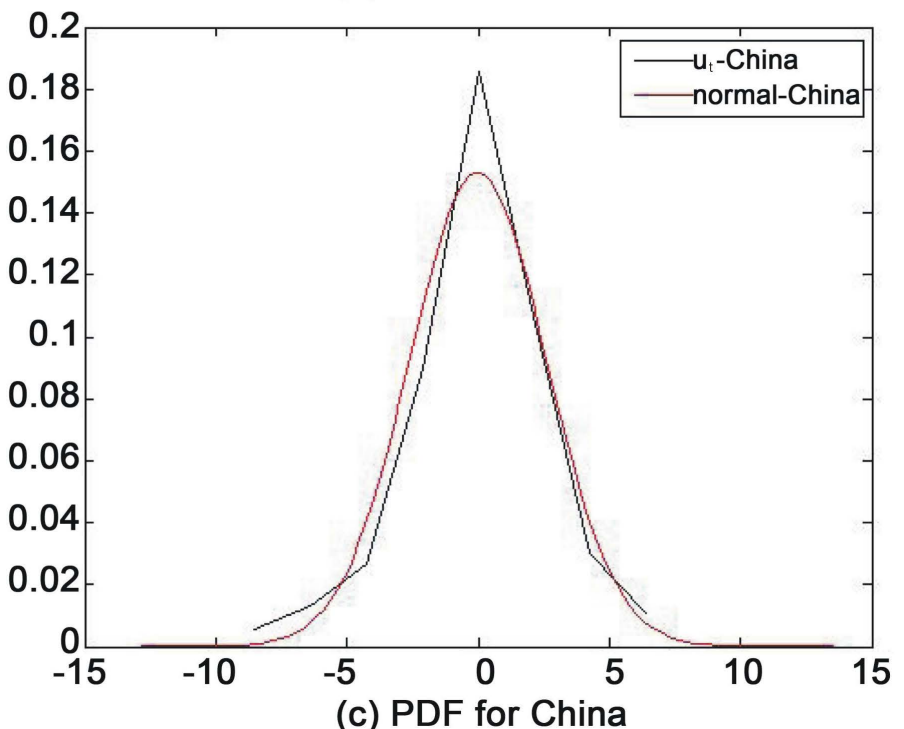

Figure 2. PDFs for reduals $\hat{u}_{t}$ and Normal $(\hat{\mu}, \hat{\sigma})$, Carhart 4-factor model. 


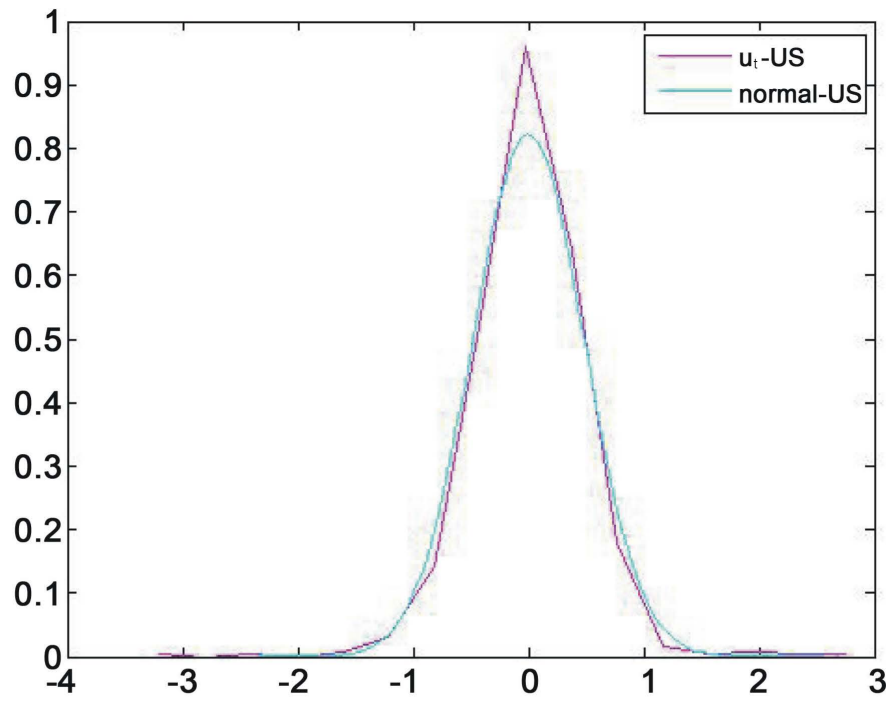

(a) PDF for US

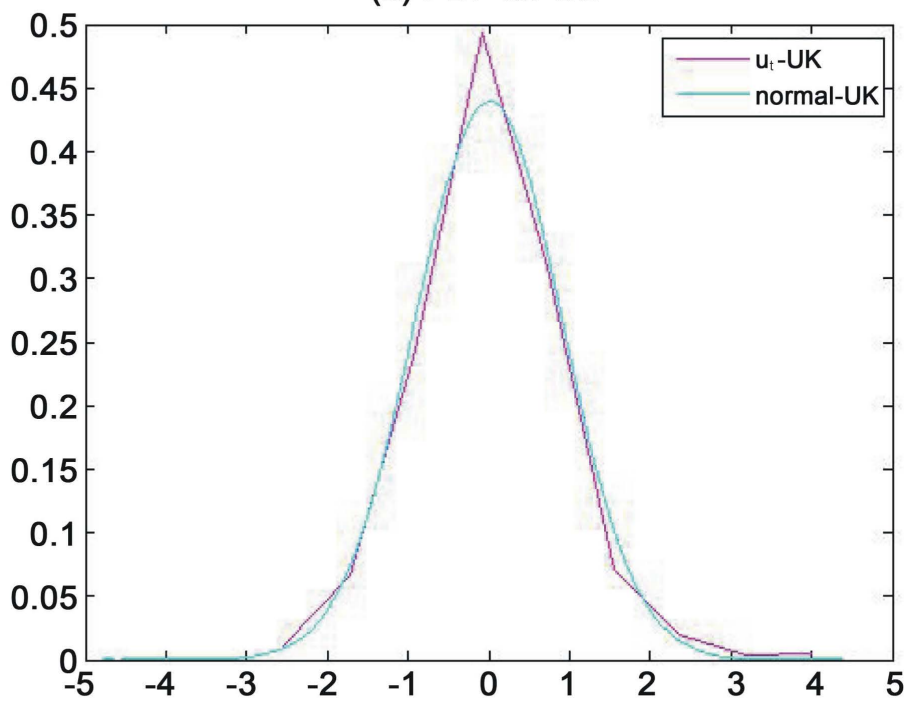

(b) PDF for UK

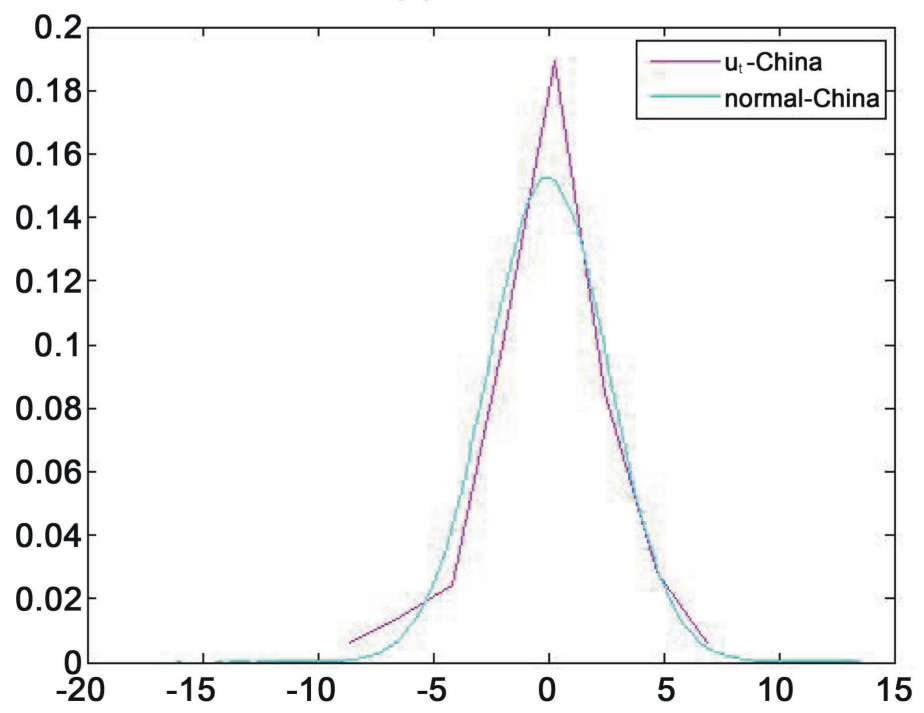

(c) PDF for China

Figure 3. PDFs for reduals $\hat{u}_{t}$ and Normal $(\hat{\mu}, \hat{\sigma})$, Fama-French 3-factor model. 


\section{Appendix 4. Simulation Results for C-SSAEPD-EGARCH Model}

In this section, we simulate the data and analyze the results to confirm that the program in MatLab is valid ${ }^{11}$. The C-SSAEPD-EGARCH $(1,1)$ model is simulated as follows.

$$
\begin{aligned}
& R_{t}-R_{f t}=\beta_{0}+\beta_{1}\left(R_{m t}-R_{f t}\right)+\beta_{2} \mathrm{SMB}_{t}+\beta_{3} \mathrm{HML}_{t}+\beta_{4} \mathrm{WML}_{t}+u_{t}, t=1,2, \cdots, T, \\
& u_{t}=\sigma_{t} z_{t}, z_{t} \sim \operatorname{SSAEPD}\left(\alpha, p_{1}, p_{2}\right) \text {, } \\
& \ln \left(\sigma_{t}^{2}\right)=a+g\left(z_{t-1}\right)+b \ln \left(\sigma_{t-1}^{2}\right) \text {, } \\
& g\left(z_{t-1}\right)=c z_{t-1}+d\left[\left|z_{t-1}\right|-E\left(\left|z_{t-1}\right|\right)\right]
\end{aligned}
$$

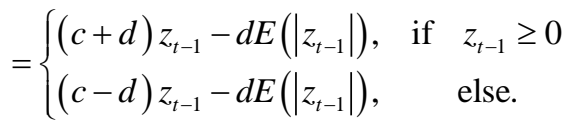

We choose $\beta_{0}=0.4, \beta_{1}=0.4, \beta_{2}=0.6, \beta_{3}=0.8, \beta_{4}=0.5, \alpha=0.5, p_{1}=p_{2}=2$, $a=0.8, b=0.2, c=0.5, d=0.5$ as the true values of the parameters. The data generation process (DGP) has following steps.

1) Given $\alpha=0.5, p_{1}=p_{2}=2$, we can generate SSAEPD random number series $\left\{z_{t}\right\}_{t=1}^{T} 12$.

2) Set the initial value $\sigma_{0}^{2}=1, z_{t}=1$, and given $a=0.8, b=0.2, c=0.5, d=0.5$, we can generate $\left\{\sigma_{t}^{2}\right\}_{t=1}^{T}$ and $\left\{u_{t}\right\}_{t=1}^{T}$, with the following formula:

$$
\begin{aligned}
& g\left(z_{t-1}\right)=c z_{t-1}+d\left[\left|z_{t-1}\right|-E\left(\left|z_{t-1}\right|\right)\right]
\end{aligned}
$$

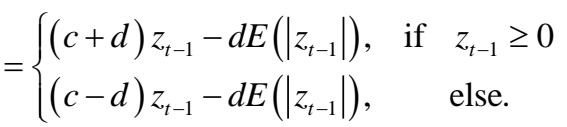

$$
\begin{aligned}
& \ln \left(\sigma_{t}^{2}\right)=a+g\left(z_{t-1}\right)+b \ln \left(\sigma_{t-1}^{2}\right), \\
& u_{t}=\sigma_{t} z_{t} \text {. }
\end{aligned}
$$

3) Generate random number series $\left\{X_{1 t}\right\}_{t=1}^{T},\left\{X_{2 t}\right\}_{t=1}^{T},\left\{X_{3 t}\right\}_{t=1}^{T},\left\{X_{4 t}\right\}_{t=1}^{T}$ from Uniform $(0,1)$.

4) Set $\beta_{0}=0.4, \beta_{1}=0.4, \beta_{2}=0.6, \beta_{3}=0.8, \beta_{4}=0.5$, and we can get $\left\{Y_{t}\right\}_{t=1}^{T}$, with the following formula:

$$
Y_{t}=\beta_{0}+\beta_{1} X_{1 t}+\beta_{2} X_{2 t}+\beta_{3} X_{3 t}+\beta_{4} X_{4 t}+u_{t}, t=1,2, \cdots, T .
$$

After getting the simulated data $\left\{X_{1 t}, X_{2 t}, X_{3 t}, X_{4 t}, Y_{t}\right\}_{t=1}^{T}$, we estimate the parameters in the $\mathrm{C}$-SSAEPD-EGARCH model. The simulation results are reported in Table 8 . The estimates from MatLab program are

$$
\begin{gathered}
\beta_{0}=0.3726, \beta_{1}=0.3988, \beta_{2}=0.5841, \beta_{3}=0.8607, \beta_{4}=0.4932, \alpha=0.5000, \\
p_{1}=2.0004, p_{2}=2.0003, a=0.8178, b=0.1894, c=0.5224, d=0.5334
\end{gathered}
$$

which are very close to the true values of the parameters. For robustness exam, we also change the true values of the parameters and redo the simulation and estimation. All the simulation and estimation show the estimates are very closed to the true values of the parameters, since all error are equal to or less than $-25 \%$.

${ }^{11}$ This MatLab program is written by $\mathrm{Mu}(2014)$.

${ }^{12}$ For the method to generate SSAEPD random variable, one can refer to Li, Tian and Zhen (2011). 
Table 8. Simulation results.

\begin{tabular}{|c|c|c|c|c|c|c|c|c|c|c|c|c|}
\hline & $\beta 0$ & $\beta 1$ & $\beta 2$ & $\beta 3$ & $\beta 4$ & $\alpha$ & $\mathrm{p} 1$ & $\mathrm{p} 2$ & $\mathrm{a}$ & $\mathrm{b}$ & c & d \\
\hline $\mathrm{T}$ & 0.4 & 0.4 & 0.6 & 0.8 & 0.5 & 0.5 & 2 & 2 & 0.8 & 0.2 & 0.5 & 0.5 \\
\hline $\mathrm{E}$ & 0.3726 & 0.3988 & 0.5841 & 0.8607 & 0.4932 & 0.5000 & 2.0004 & 2.0003 & 0.8178 & 0.1894 & 0.5224 & 0.5334 \\
\hline $\mathrm{P}$ & $6.86 \%$ & $0.29 \%$ & $2.65 \%$ & $-7.59 \%$ & $1.35 \%$ & $0.00 \%$ & $-0.02 \%$ & $-0.01 \%$ & $-2.23 \%$ & $5.29 \%$ & $-4.48 \%$ & $-6.67 \%$ \\
\hline $\mathrm{T}$ & 0.4 & 0.4 & 0.6 & 0.8 & 0.5 & 0.5 & 2.2 & 2.2 & 0.8 & 0.2 & 0.5 & 0.5 \\
\hline $\mathrm{E}$ & 0.3812 & 0.4139 & 0.6067 & 0.8207 & 0.5078 & 0.5000 & 2.0000 & 2.0000 & 0.8040 & 0.2072 & 0.4997 & 0.4969 \\
\hline $\mathrm{P}$ & $4.69 \%$ & $-3.47 \%$ & $-1.11 \%$ & $-2.59 \%$ & $-1.56 \%$ & $0.00 \%$ & $9.09 \%$ & $9.09 \%$ & $-0.50 \%$ & $-3.59 \%$ & $-0.06 \%$ & $0.61 \%$ \\
\hline $\mathrm{T}$ & 0.4 & 0.4 & 0.6 & 0.8 & 0.5 & 0.6 & 2 & 2 & 0.8 & 0.2 & 0.5 & 0.5 \\
\hline $\mathrm{E}$ & 0.4352 & 0.3886 & 0.6135 & 0.8003 & 0.4273 & 0.5000 & 2.0000 & 2.0000 & 0.8010 & 0.2015 & 0.5078 & 0.4854 \\
\hline $\mathrm{P}$ & $-8.80 \%$ & $-2.85 \%$ & $-2.26 \%$ & $-0.04 \%$ & $14.55 \%$ & $16.67 \%$ & $0.00 \%$ & $0.00 \%$ & $-0.13 \%$ & $-0.76 \%$ & $-1.56 \%$ & $2.92 \%$ \\
\hline $\mathrm{T}$ & 0.4 & 0.5 & 0.5 & 0.5 & 0.8 & 0.4 & 2 & 2 & 0.8 & 0.2 & 0.5 & 0.5 \\
\hline E & 0.3410 & 0.5027 & 0.5344 & 0.5232 & 0.8461 & 0.5000 & 2.0000 & 1.9994 & 0.7919 & 0.2042 & 0.5122 & 0.4891 \\
\hline $\mathrm{P}$ & $14.75 \%$ & $-0.53 \%$ & $-6.89 \%$ & $-4.64 \%$ & $-5.76 \%$ & $-25.00 \%$ & $0.00 \%$ & $0.03 \%$ & $1.01 \%$ & $-2.10 \%$ & $-2.44 \%$ & $2.17 \%$ \\
\hline $\mathrm{T}$ & 0.6 & 0.4 & 0.6 & 0.8 & 0.5 & 0.5 & 2 & 2 & 0.8 & 0.2 & 0.5 & 0.5 \\
\hline $\mathrm{E}$ & 0.5850 & 0.4194 & 0.6900 & 0.8004 & 0.4666 & 0.5000 & 1.9999 & 2.0000 & 0.8129 & 0.1944 & 0.5110 & 0.5046 \\
\hline $\mathrm{P}$ & $2.50 \%$ & $-4.86 \%$ & $-15.00 \%$ & $-0.05 \%$ & $6.68 \%$ & $0.00 \%$ & $0.00 \%$ & $0.00 \%$ & $-1.62 \%$ & $2.79 \%$ & $-2.20 \%$ & $-0.91 \%$ \\
\hline $\mathrm{T}$ & 0.4 & 0.4 & 0.6 & 0.8 & 0.5 & 0.5 & 2 & 2 & 1.5 & 0.2 & 0.5 & 0.5 \\
\hline $\mathrm{E}$ & 0.3022 & 0.4876 & 0.5881 & 0.8504 & 0.5868 & 0.5000 & 2.0000 & 1.9999 & 1.5154 & 0.1904 & 0.4940 & 0.4798 \\
\hline $\mathrm{P}$ & $24.46 \%$ & $-21.91 \%$ & $-1.99 \%$ & $-6.30 \%$ & $-17.35 \%$ & $0.00 \%$ & $0.00 \%$ & $0.00 \%$ & $-1.02 \%$ & $4.82 \%$ & $1.20 \%$ & $4.03 \%$ \\
\hline $\mathrm{T}$ & 0.4 & 0.4 & 0.6 & 0.8 & 0.5 & 0.5 & 2 & 2 & 0.8 & 0.6 & 0.5 & 0.5 \\
\hline E & 0.4304 & 0.3809 & 0.6067 & 0.7838 & 0.5133 & 0.5000 & 2.0002 & 2.0001 & 0.8090 & 0.6013 & 0.5165 & 0.5135 \\
\hline $\mathrm{P}$ & $-7.59 \%$ & $4.77 \%$ & $-1.12 \%$ & $2.03 \%$ & $-2.65 \%$ & $-0.01 \%$ & $-0.01 \%$ & $-0.01 \%$ & $-1.33 \%$ & $-0.22 \%$ & $-3.31 \%$ & $-2.70 \%$ \\
\hline $\mathrm{T}$ & 0.4 & 0.4 & 0.6 & 0.8 & 0.5 & 0.5 & 2 & 2 & 0.8 & 0.2 & 0.6 & 0.5 \\
\hline $\mathrm{E}$ & 0.3313 & 0.3850 & 0.6394 & 0.8438 & 0.5452 & 0.5000 & 2.0000 & 2.0000 & 0.8041 & 0.1906 & 0.6023 & 0.4796 \\
\hline $\mathrm{P}$ & $17.19 \%$ & $3.75 \%$ & $-6.57 \%$ & $-5.47 \%$ & $-9.04 \%$ & $0.00 \%$ & $0.00 \%$ & $0.00 \%$ & $-0.51 \%$ & $4.71 \%$ & $-0.38 \%$ & $4.08 \%$ \\
\hline $\mathrm{T}$ & 0.4 & 0.4 & 0.6 & 0.8 & 0.5 & 0.5 & 2 & 2 & 0.8 & 0.2 & 0.5 & 0.6 \\
\hline $\mathrm{E}$ & 0.4011 & 0.4294 & 0.5951 & 0.7737 & 0.4767 & 0.5001 & 2.0003 & 2.0004 & 0.7940 & 0.1974 & 0.5099 & 0.5715 \\
\hline $\mathrm{P}$ & $-0.28 \%$ & $-7.36 \%$ & $0.82 \%$ & $3.29 \%$ & $4.65 \%$ & $-0.01 \%$ & $-0.01 \%$ & $-0.02 \%$ & $0.74 \%$ & $1.29 \%$ & $-1.99 \%$ & $4.75 \%$ \\
\hline
\end{tabular}

Notes: $\mathrm{T}$ means the true value of parameters. E means the estimates. P means the error in percentage.

Hence, we conclude the MatLab program can be applied to estimate and analyze empirical data for C-SSAEPD-EGARCH.

\section{Appendix 5. US 4 Factors and Global 4 Factors}

In this section, we compare the US 4 factors and the Global 4 factors. Data are downloaded from the French Data Library. Because of data availability, we only analyze the monthly data for UK software \& computer services sector. Table 9 shows the descriptive statistics of US 4 factors are close to those of Global 4 factors, which shows the strong global effects of US stock market. Estimates in the 
Table 9. Descriptive statistics.

\begin{tabular}{ccccccccc}
\hline & Mean & Med. & Max. & Min. & St.De. & Ske. & Kur. & P \\
\hline & & \multicolumn{2}{c}{ Panel A: 2003:10 to 2015:10, monthly } & & \\
\hline UK & 0.97 & 1.10 & 14.35 & -19.51 & 5.53 & -0.60 & 4.65 & 0.00 \\
Global ME & 0.66 & 1.24 & 11.42 & -19.46 & 4.50 & -0.87 & 5.51 & 0.00 \\
Global SMB & 0.04 & -0.16 & 3.84 & -3.52 & 1.51 & 0.04 & 2.60 & 0.50 \\
Global HML & 0.10 & 0.10 & 4.34 & -4.79 & 1.58 & -0.12 & 3.44 & 0.40 \\
Global WML & 0.48 & 0.66 & 9.22 & -23.89 & 3.40 & -2.80 & 20.74 & 0.00 \\
US ME & 0.69 & 1.35 & 11.35 & -17.23 & 4.19 & -0.72 & 4.94 & 0.00 \\
US SMB & 0.12 & -0.03 & 5.79 & -4.25 & 2.29 & 0.15 & 2.50 & 0.29 \\
US HML & 0.09 & -0.03 & 7.65 & -9.67 & 2.31 & -0.33 & 5.30 & 0.00 \\
US WML & 0.13 & 0.35 & 12.45 & -34.58 & 4.66 & -2.98 & 23.28 & 0.00 \\
\hline
\end{tabular}

Note: The null hypothesis of JB test is H0: Data are distributed as Normal $(0,1)$.

Table 10. Estimates.

\begin{tabular}{|c|c|c|c|c|c|c|c|c|c|c|c|c|c|c|}
\hline & $\beta 0$ & $\beta 1$ & $\beta 2$ & $\beta 3$ & $\beta 4$ & $\alpha$ & p1 & $\mathrm{p} 2$ & $\mu$ & $\sigma$ & a & $\mathrm{b}$ & c & $\mathrm{d}$ \\
\hline & \multicolumn{14}{|c|}{ Panel A: C-SSAEPD-EGARCH } \\
\hline UK in Global & $0.59^{*}$ & $0.72^{*}$ & $0.44^{*}$ & $-0.39^{*}$ & $-0.14^{\star}$ & $0.45^{*}$ & $1.79^{*}$ & $1.78^{*}$ & - & - & $0.60^{*}$ & $0.79^{*}$ & $0.12^{*}$ & $0.16^{*}$ \\
\hline \multirow[t]{2}{*}{ UK in US } & $0.36^{*}$ & $0.78^{\star}$ & $0.20^{*}$ & $-0.31^{*}$ & $-0.08^{\star}$ & $0.49^{*}$ & $1.70^{*}$ & $1.70^{*}$ & - & - & $0.51^{*}$ & $0.41^{*}$ & $0.13^{*}$ & $0.32^{*}$ \\
\hline & \multicolumn{14}{|c|}{ Panel B: C-Normal } \\
\hline UK in Global & $0.44^{*}$ & $0.76^{*}$ & $0.45^{*}$ & $-0.40^{*}$ & $-0.12^{*}$ & - & - & - & 0.00 & 4.25 & - & - & - & - \\
\hline \multirow[t]{2}{*}{ UK in US } & $0.33^{*}$ & $0.81^{*}$ & $0.26^{*}$ & $-0.45^{*}$ & $-0.13^{\star}$ & - & - & - & 0.00 & 4.11 & & & & \\
\hline & \multicolumn{14}{|c|}{ Panel C: FF-Normal } \\
\hline UK in Global & $0.36^{\star}$ & $0.78^{*}$ & $0.43^{*}$ & $-0.33^{*}$ & - & - & - & - & 0.00 & 4.27 & - & - & - & - \\
\hline UK in US & $0.28^{*}$ & $0.85^{*}$ & $0.23^{*}$ & $-0.37^{\star}$ & - & - & - & - & 0.00 & 4.14 & - & - & - & - \\
\hline
\end{tabular}

Note: C-Normal is the model used in Carhart (1997). FF-Normal is the model used in Fama-French (1993).

Table 11. P-values of KS test.

\begin{tabular}{cccc}
\hline model & C-SSAEPD-EGARCH & C-Normal & F-Normal \\
\hline UK in Global & 0.48 & 0.00 & 0.00 \\
UK in US & 0.58 & 0.00 & 0.00 \\
\hline
\end{tabular}

Note: The null hypothesis of KS test is H0: Data follow a specified distribution. We set the significance level of all tests at $5 \%$. If the P-value of KS test is bigger than $5 \%$, then we do not reject the null hypothesis. Otherwise, we reject the null hypothesis.

Table 12. AIC values.

\begin{tabular}{cccc}
\hline model & C-SSAEPD-EGARCH & C-Normal & F-Normal \\
\hline UK in Global & 6.15 & 5.83 & $5.82^{\star}$ \\
UK in US & 5.88 & $5.76^{\star}$ & $5.76^{\star}$ \\
\hline
\end{tabular}

Note: *marks the smallest AIC value for each return.

mean equation (Table 10) are all statistically significant. P-value of KS test (Table 11) results shows all models pass the residual test. Table 12 shows Fama-French (1993)'s 3 factor model is better with the lowest AIC values. 
Submit or recommend next manuscript to SCIRP and we will provide best service for you:

Accepting pre-submission inquiries through Email, Facebook, LinkedIn, Twitter, etc. A wide selection of journals (inclusive of 9 subjects, more than 200 journals)

Providing 24-hour high-quality service

User-friendly online submission system

Fair and swift peer-review system

Efficient typesetting and proofreading procedure

Display of the result of downloads and visits, as well as the number of cited articles Maximum dissemination of your research work

Submit your manuscript at: http://papersubmission.scirp.org/

Or contact jmf@scirp.org 